\section{SUSTAINABILITY OR SUSTAINABLE DEVELOPMENT: AN ANTHROPOLOGICAL PERSPECTIVE}

Shambhu Prasad Kattel

\section{General Introduction}

The essay discusses the concept of sustainability and adaptation pattern of the Kumals of Tumlingtar in different situations as well as the fruitfulness of the concept of 'sustainability' in understanding different dimensions of adaptation among human population. The essay is divided into four sections. First section gives general introduction of the concept 'sustainability' and 'adaptation'. Second section presents some arguments to clarify the concepts dealing with different aspects of sustainability and dimensions of adaptation. In the third section, I have presented a case material from Arun Valley based on my field experience and finally the last section holds conclusion of the essay.

\section{Introduction: Background to the Concept}

Sustainability or sustainable development is among the frequently used term in the present development literatures. Their main focus is the present rate of environmental degradation, increasing human population, their demand, growing pollution of air and water and its probable present as well as future solutions. The concept 'sustainability' alerts human beings to make a balance between natural resources and population and to manage the resources towards the betterment of environment, health, economic growth and equity, in which situation maximum population can manage good quality of life (Wikan 1995). This concept became famous in the public discourse after the report of the World Commission on Environment and Development of the United Nations. It was known as Brundtland commission (1987). It stated that sustainable development is development that meets the needs of the present generation without compromising the ability of future generation to meet their needs (cf. Sach 1997). The definition gives the meaning that sustainability is the situation where human needs are fulfilled without disturbing the future.

In ecological anthropology, the discourse came as a humanenvironment relationship. Environmental threats to human health and human threats to the environment are a major source of concern throughout the world. The problem of how to live sustainably in different types of socio-cultural and physical context is widely recognized as one of the most daunting challenges today (Milton 1997). We can see various plans in the name of environmental management, bio-diversity conservation, and sustainable development and some programs are implemented for the betterment of the local people. On the contrary, the objected groups are forced to change their basic economic activities. For example, Malagasy responded as, "the next time you come to Madagascar, there will be no more Malagasy. All the people will have starved to death and a lemur will have to meet you at airport (Kottak 1997). They mean that donors are worried about the lemur, plants and the environment instead of the human population. Thus, sustainability is an ambiguous concept, with different meanings and dynamic situations, the situation changes due to other factors such as population growth, exploitation and condition of renewable and non renewable resources, development of technology, socio-cultural changes and according to the changes of human needs. 
To understand the discourse on sustainability, we should understand the present world in general. The world is divided into developed and underdeveloped. The underdeveloped countries are facing problems of health, food and shelter and the population depleting natural resources for their survival, producing more children for the help to their future (Meadows et. al. 1992). The developed nations have different needs, produce vehicles, chemical fertilizers, pesticides, weapons, plastic utensils etc., which play a vital role in increase air and water pollution and in the degradation of environment as well.

Human beings need energy for their survival and continuity of life, which they get from the environment. Natural resources are limited where as human needs are unlimited. Growth is possible only up to the limit. Carrying capacity is concerned for us, which means availability of suitable conditions for living determines what population of an organism can exist in an environment (Hardesty 1977, Hawley 1986, Moran 1969). Human beings are expanding facilities through technology so high level of degradation in environment and natural resources is taking place. When bottleneck situation of human appeared due to degradation of environment, shortage of natural resources and problem of water and air pollution, the concept "sustainability" came into discourse among the scholars concerned to the issue and in human ecology. There are various views in ecological anthropology regarding sustainability (will be dealt in conceptual argument).

However, I found the concept "sustainability" more ambiguous and obscure. Some questions strike my mind regarding the concept of sustainability. What is sustainability or sustainable development? What type of sustainable development, for whom and how? What are the aspects of sustainability? Are they same dimensions of human adaptation? Does it help to understand human adaptation?
What is the meaning of micro and macro level adaptation or sustainability?

I will seek answers to these questions from my own fieldwork of the Kumals community of Arun Valley in Eastern Nepal. I had carried out the fieldwork two times in 1997 and 1999. Altogether I stayed in the field about 7 months and collected the information using anthropological methods like observation, progressive contextualization, key informant interviews and focus group discussions. I participated in most of the family as well as community decisions, discussions, socio-cultural functions and in fairs and festivals. From human ecological perspective I found fascinating data due to rapidly changing socio-cultural, economic and environmental circumstances of the Kumals. Competitive behaviour among the Kumals and between Kumals and nonKumals, shortage of common property resources, obstacles in traditional occupations, influence of modern money and market, introduction of development activities and so on are the distinct characteristics of Arun Valley. In this article, I will present the case material of Kumals, their present challenges and their effort to cope with the changing environment on the way to sustainability.

\section{Conceptual Arguments}

Sustainability as a concept carries the meaning of sound ecological, economic, political and socio-cultural development of an area or of a group of people. I argue that ecological sustainability means better environment for any given population with sufficient natural resources, unpolluted air, water and sufficient resources not disturb regeneration. Population under carying capacity of land and resources is ecological sustainability. Economic sustainability means sound distribution of means of production among community members, maximum equity and management of economies without disturbing the environment for future. 
Regarding political sustainability I agree with David Pearce (1997) that it is life of the people without fear. Socio-cultural sustainability means the knowledge, skill and capabilities of people with rights to expression, right to learn, sharing, participation and equality of opportunity.

Sustainability as a concept gives a broad meaning and it is not possible to achieve all aspects at a time. Different scholars argue with their own aspects and point of view. Haaland et al (1979) and Storaas (1997) use the term viability and show ecological, economic and political linkages between farmers and pastoralists, which is similar to the term sustainability. David Pearce (1997) mentioned that sustainability must be measured by progress along the vector made up of attitudes that include improvement in income and its distribution, in health, education, freedom and access to the resources. In my view, sustainability is the better balance between human population and available resources and relatively better environmental situation, fulfilling maximum needs of human beings adapting easily in the environment.

For Hawley adaptation is a collective process. Human beings struggle to be sustained in an environment through association of organism: the family, tribe, state, etc. as a social unit (1986) thus, focuses only on behavioral adaptation. An individual always tries to adapt in natural as well as social environment (Barth 1984). In deed, sustainability also has two aspects, i.e. biophysical and socioeconomic. Biophysical means the relationship with the environment, the earth, forest, water, air, etc. and socio-economic means the human needs or culturally constructed things. Adaptation is a self-regulating process affected by micro and macro orders (Rappaport 1979). I have used the term micro and macro level because in micro level, an individual/household interacts in the environment through his biological, socio-cultural, political, and economical abilities. According to Barth, these are the dimensions of niche that affect the human adaptation (1984). Sometimes, adaptation of an individual/household is negatively affected by the national and international level decisions. At other times, these macro level decisions appeared as maladaptive in micro level, which might be adaptive in macro level.

Haaland (1991) case material proves that helps of government and donor agencies work negatively to the locals. This is an example of macro level decision and its impact on the locals. According to him, Beja community of Western Sudan was self-sufficient, sustained, and able to cope with the environment even though they hit by drought frequently. As earlier, drought hit Derudeb of SavannaSahel zone of Sudan in early eighties. As a result, donor agencies came to help the victims. Government also introduced various environmental management and poverty alleviation programs with the support from the donor agencies. On the contrary, forest/green land changed into desert and environment became harsh due to over population and their activities. Market economy influenced the Beja and they get involved in cutting trees for making charcoal to earn money. As a result, the Bejas who were sustained in the environment for more than 200 years became maladaptive from the macro level decisions of state and donor agencies.

An anthropologist, Unni Wikan (1995), very interestingly describes sustainability, not from natural perspective but from cultural perspective. She studied some poor families of Cairo, a capital city of Egypt, and dealt the concept, "sustainable development". Leaving the general trend, she described sustainable or adaptation strategy of city dwellers. According to her, rural poverty may be a threat to natural resources, but urban poverty seems to be even a greater threat to social and cultural resources. Sustainable development in the city means growth of cultural and social as well as 
material assets. According to her, all the poor families of Cairo regarded themselves as poor, and other people also treated them as poor. During her study she found out that all the poor families were trying to sustain themselves by developing cultural competency. She argues that if sustainable development means to maintain legitimate needs then the poor family of Cairo trying to manage good food, shelter, health, environment, etc. for the future then certainly the poor families of Cairo were developing cultural competency towards sustainable life.

The poor were acquiring knowledge, skills, attitudes, and institutional practices as copying mechanisms. Like preservation and improvement of natural resources the poor families are considering cultural values and competency as a part of their life and managing day-to-day life as middle class families. Similarly, making future for the children is an important aspect of sustainability. Mothers of new generation are educated, teach their children at home which helps in reducing tuition fees. From the mothers children also learn politeness, obedience, good language, and respect to their parents and elders. Marriages are made with an individual decision. After marriage the new couple settle in a new house and started saving for their future for better food, clothing, equipment and so on that helps them to uplift their social status. Instead of bride price, the groom lives in the girl's house. Ornaments of the wife are used to buy household goods such as refrigerator, washing machine, television, etc. since material (fixed) assets are considered more valuable in cities. People want to gather fix assets as much as they can because they want to show the society their status. Saving and investing for future is an economic aspect of sustainability, where all poor actively participates in saving clubs which provide them interest free loan that they invest in building and other assets. Neither a woman drinks in the back stage nor a man is intoxicated because they keep in view of their children's future. Each household member has a feeling, 'I'm better than others' and always think that what they are doing is for their children's sake, and emphasize that one should do it.' The neighbors do not quarrel as before instead they develop a social network among themselves. Thus, Cairo's poor families are maintaining life coping with the current environment and building competency towards sustainability. Based on these perspectives, I am going to describe the present coping strategy of the Kumals of Arun valley towards sustainable future.

\section{The Kumals of Arun Valley: Struggle for Sustainable Development}

Arun valley is situated in the eastern hilly region of about $500 \mathrm{kms}$ east from the capital city Kathmandu, Nepal. This valley is located in the lap of the Arun and Sabha rivers. The Arun river is known as Koshi in Terai. The valley has various climatic zones, different species of plants, birds and wildlife. A beautiful flatland, Tumlingtaar, is situated in the valley in between the Arun and Sabha rivers. Tumlingtaar is situated at an elevation of about 700 to 1200 meters above the sea level. At present about 600 Kumals are inhabited in Tumlingtar. The valley is known as Maj Kirant; a main habitat of the Rais. After the unification of Nepal, all Jat or Jatis (caste groups) arrived and settled in Tumlingtar. Here, I want to focus on so-called low caste group, the Kumals, and their efforts to cope with environment in sustainable way under different circumstances.

The Kumals are pottery-making Jati (caste), who came with the conqueror group during the unification, and settled down in Tumlingtaar as state representatives (tax collectors and administrators). Tumlingtaar having a fertile land covered with dense forests and some clay mines useful for making pottery, the Kumals soon attracted towards making pottery and agriculture, which was 
possible because of accessibility of enough natural resources. They became famous around the surrounding area because of pottery and continued doing it for more than 200 years and attain sustainability. With the establishment of development activities and introduction of market economy the people lost their land, traditional occupation, natural resources, traditional practices and thus resulting a loss of sustainable life (Kattel 2000). In this state of instability, they are facing high competition with other groups but are still trying to sustain in various ways.

\section{Development Activities and Changing Sustainable Life of Kumals}

Tumlingtar airport was constructed confiscating Kumal's land in 1965. Arun III project office was established in Tumlingtaar buying about 20 hectares land of Kumals. Other high caste peoples were also attracted towards this place so they came here and settled down buying land, where only Kumals and Majhis used to live earlier. After the establishment of Makalu Barun Conservation Area Project (MBCAP) and introduction of Makalu Base Camp for Makalu mountain expedition, the valley became a tourist area. As a result, Tumlingtaar developed as a business center. This accelerated flow of migration to Tumlingtar and established hotels and lodges, groceries and retail shops. The area came under Khandbari municipality soon, developed amenities like telephone, drinking water and electricity and some offices also established. During the process of development Kumals lost about 70 percent of their land, traditional pottery occupation, forest and clay resources and traditional practices. The new migrants were powerful economically and politically and privatized the common resources, especially the forests. They constructed well-furnished wooden houses in the bazaar destroying the surrounding forests. Some of the clay mines were closed during the airport construction while the new migrants restricted the rests. This forced the Kumals to accept new lifestyles. Fast foods, modern technology, and uses of plastic utensils displaced them from their traditional niche and sustainable life.

Kumals realized the situation a little later when their ancestral occupation pottery stopped and faced daily hand to mouth problem. Under this situation, they developed new values adapting new circumstance, which is described below.

\section{Nature Culture Relationship and Sustainability}

There are various theories in anthropology regarding nature culture relationship (Milton 1997, Ingold 1992). In the community of Kumals, I found deep relationship between nature and culture. They had five forests in the surrounding area and some clay mines. They believed that they should use only one forest and one mine at a time i.e. per year, which they were doing in practice. They believed that if such restriction is not followed then the forest deities will get angry and various natural calamities will happen. They worship forest deities twice, before and after the use of clay mines and forests and sacrifice animals. They also offer some portion of new crop to the deities after harvesting. Besides this they have the belief that the herbal plants that grew in the forests should not be picked or chopped except the shamans. Although this kind of beliefs seemed to be traditional and old fashioned this has greatly helped in protecting the environment and unnecessary use of natural resources.

As I mentioned earlier, because of the thick settlement almost all the forest land changed into shrubs and bush land due to which the Kumals had faced shortage of forest products. This was because of the new settlement and improper used of forest products and natural resources not following the local beliefs. More than any other 
groups, Kumals were affected very badly due to shortage of forest resource. After sometimes, they realized their situation and weakness and formed an organization of Kumals in 1999 in the leadership of some literate Kumals. They also formed community forests in their leadership ${ }^{\prime}$ and started protecting the forest. Thereafter, nobody is allowed to enter the forest without permission of the committee members. Grazing is totally prohibited in the community forest. Some of the Kumals also joined the neighboring forests. They protected local sources of water and made cemented wells and taps. Plantation is done in the forest area as well as near the water sources. More than seven households have drinking water in their own houses now. All women of the community are well aware of sanitation and health. Many families have planted Sisau (Dalbergia Sissoo) and timber trees in their private land, which is also used as fodder for the cattle. As before, they have started worshipping forest in the name of Sansari Pooja, Udhauli and Ubhaunli which shows that Kumals are concerned in gaining the greeneries and water resources for their better future.

Local Knowledge and Practices towards Sustainability: In the past Kumal families raised pigs, goats, sheep, and oxen as a earning for living. Children and elders looked after the livestock whereas the youth performed the other activities. Few families still have shift camping to look after the livestock. The majority of the Kumals are grazing their livestock in the surrounding pasture of riverbanks these days. The pasture is not sufficient during winter so they have reduced the number of their cattle and involved in portering and other occupation for survival. In earlier days, herdsman got involved in other activities in winter, like carrying salt and grain and chemical fertilizers from Terai, clay from mines, collecting fuel wood from forest for the rainy season etc.
Similarly, Kumals are involved in farmland cultivation from May to September and December to April is for pottery making where as October and November is marked for celebrating different festivals. Dashain festival is one that falls during October and November, which is celebrated for ten days. Traditionally, most of the pigs, goats, sheep and chickens raised are slaughtered in this festival honoring to different gods and goddesses. The meat is shared with relatives and neighbors. The strain of continuous and heavy working days for five months is regained during this festival. Similarly, energy lost while carrying clay from mines and selling pots are also regained eating delicious food and meat and with enjoyment.

\section{Soil Management}

The pottery making occupation in one hand or other helped in maintaining soil fertility. Tree leaves are obtained as fodder, the green twigs are used in fencing and during winter it is use for drying potteries. Thus produced ashes act as fertilizers and shifting of terraces each time while drying potteries make the land fertile. Similarly, shifting of livestock-shed is also shifted due to which the manure also acts as fertilizers and leaf litters used as animal bedding also becomes manure.

The Kumals along with raising livestock also takes up farming which has several positive linkages such as investment, manure, fodder, food, etc., (See Haaland et al. 1979). This kind of linkages and soil management helped them for long -term sustainability.

\section{Improving Socio-cultural environment}

As I mentioned above Kumals are considered as a low caste group because of their occupation and socio-cultural practices. As high caste Hindus, they do not take menstruated women as impure or 
dirty. They do not use Brahmin priest in their rituals. They do not have hard and fast rules on touchability and untouchability. Regarding the death rituals it ends up with a feast slaughtering pigs attended by close relatives, neighbours and mourners. In addition to this, it looks like a practice that without a cup of local brew a Kumal does not open his eyes in the morning and close in the evening. So, high caste people satirically characterized them as "Bhadau Lagyo Kumale Teda-Teda Bat, Chaitra Lagyo Kumale Purporo Ma Hat". It literally means Kumals cannot speak due to over drinking in the harvesting season and regret in May when finished all cereals (cereals are used to make home made wine). But after the formation of Kumal organization they have now decided to stop drinking brew, making clay pots and follow their traditional culture and practices. On the contrary, all Kumals agreed to follow the high caste values/cultures and practices. Nowadays, Kumals are identified by clan names, used Brahmin priest to carry out various rituals, stopped bride price practice, and alcohol drinking to gain the social, political and symbolic capitals ${ }^{2}$ as other high caste groups. Nowadays, people cannot find the Kumals at Tumlingtaar because none of them identify as Kumals and have started writing their clan names such as Halide, Phathake, Dudhpau, Mudula, Bhattarai, etc. As other groups, they perceive menstruated women as impure, do not receive bride price. As in high caste Hindus, Brahmin is accepted as their priest. During my stay in Tumlingtaar I found that five of the Halide families performing the Shradda (worshipping the ancestors which is performed annually) as high caste groups. Nowadays, social seclusion and caste disparity has been decreased in Tumlingtar.

Furthermore, all individuals of the Kumal community, even though they are not their own kin, have started giving fictitious relations like Mama-Maiju, Kaka-Kaki, Hajurba-Hajurama, Didi-Bhinaju and so on and are living in a group. Kumals have made this relationship to strengthen their group adaptation because one can help other during troubles. This type of relationship developed among the Kumals also helps to attain sustainability.

\section{Improving Economic Condition and life Style:}

Almost all Kumals are aware of the value and importance of money. They do not depend only on agriculture and pottery making as before. Most of the youths are known as good porters. They carry heavy loads for the local shops and groceries as well as for the tourists. Some youths have gone to Gulf countries to earn money. Two of the families have installed teashops. Some farmers started producing seasonal vegetables and supply it to local hotels and market. Old generation blame the new generation as money minded. The new generation do not drink brew, do not celebrate festivals and do not play card as the old generation. Instead of drinking local brew of millet they sell it in the market and buy tea and sugar. A seventy-six years old man, Lalibung Kumal, said about his property "all this land and property was mine but my son does not allow me to drink brew instead he gives me a cup of tea, all my son needs is money, not culture". On the contrary, the young generations say, "we have to buy everything now, the clothes, spices, foods and fertilizers and also spend money for schooling children so we need money". Drinking brew is not also good for health. They started family planning for a better future of their children. Most of the Kumal men worked as porters, wage laborers and so on whereas women are involved in vegetable and poultry farming and producing as well as selling local wine in the local market. Nobody stays without doing anything. An NGO, Rural Reconstruction Nepal, has helped in forming various women saving and credit groups. I found that about $70 \%$ of Kumal women were involved in such groups where they save money in a monthly basis and also get loans at a cheap interest rate. In Non-Kumals' view, 
Kumals have changed a lot. They do not drink beer, do not wear traditional clothes, send children to school, work hard to earn a living. All these activities of Kumals are towards a sustainable life.

\section{Learning Middle class culture}

Cooperation and mutual help is increased within the Kumal community. Children from all houses have started going to schools. Houses and yards looks neat and clean, wash utensils daily and use toilets as other people of the surrounding does. Young generation does not speak Kumal language. They wear modern clothes as other people of so called upper caste wore. Now politeness and cooperation became a part of the Kumal culture. Everyone speak very politely with strangers. At the first meeting, they say, Namaste to a stranger (Nepali word for greeting) and ask, "Shall I help you?" Actually, Kumals learnt this culture from the contact of tourist and outsiders. Some of the Kumals are even elected in local political organizations as ward chairperson and ward members. The main aim of these elected politicians is to solve local problems of their community.

Among the Kumals they have various forms of cooperation like Sagaune, Guhardine and Parma. One helps the other during marriage and death rituals which is known as Sagaune. Similarly, providing help during building houses and labor work is known as Guhardine. Parma is a labor exchange system, which is mostly used in farming. Thus, at present mutual help and cooperation become common practice in Kumal community. However, Kumals have developed cultural competency to cope with the present situation. They have modified and adopted the present strategy (competency) disturbing their traditional and cultural practices Indeed, some of them proved to be maladaptive and migrated from the area wit: came into contact with development interventions and non-Kumals. To be adaptive in the changing environment the remainders of
Tumlingtaar decided to change themselves. In my view, all these activities of the Kumals at present are for better future or sustainability.

\section{Concluding Remarks}

From the above discussion, it is cleared that the term sustainability gives the meaning of fulfillment of maximum needs of human beings at present as well as for future without disturbing the environment. Achieving sustainability seems almost impossible because of various reasons in present situation of the world. In spite of the obstacles that might come reaching our destination we can work towards a better future and can prevent hazards to some extent. Therefore, I conclude that sustainability means a good balance of human population, their needs and the environment in a long term. We can see that the concept of sustainability is used differently by different scholars. I think, more or less all scholars are in the consensus that sustainability is situational and it is the state of maximum balance of the demands of population and fulfillment of their needs without disturbing the environment. A similar balance between population and their environment is often portrayed in anthropological studies of adaptation.

We should not be concerned in only one aspect i.e. environmental/ ecological sustainability. To keep a better balance between population and resources, socio-cultural, economic, and political aspect of society should also be considered. Therefore, at present various scholars have raised issues of socio-cultural, political and economic sustainability (Pearce: 1997, Sotras: 1997, Wikan 1995). I would like to conclude the case of Kumals considering different aspects of sustainability.

According to Haaiand, local pre-modein societies followed some local rules and practices to protect their environment and manage 
their life sustainably even in hazardous situations. The case of Kumals also proves this saying. The Kumals have developed sociocultural, economic and political practices towards sustainability through their experiences. Development activities and modern facilities of Tumlingtar alienated the Kumal community from their land resources, occupation and traditional practices but with extreme effort they were able to achieve sustainability. From these cases, we might say that pre-modern societies and their adaptation patterns are more sustainable than the modern external factors affecting societies at micro level. In communities, national and international decisions on political economy has introduced dependency among the people in various aspects of their lives: By nature human beings try to cope up in different environments by developing new socio-economic and cultural values but sometimes they may not succeed. For instance, in the new situation, the Kumals tried to get sustained in various ways but some families were not able to manage to do so and were displaced from their habitat.

Sustainability at macro level might not be similar as in the micro level. The case of Kumals indicates of such. Let me elaborate this with another example. The Makalu Barun Conservation Area Project was established in Arun valley by the state with financial support from ODA for the conservation of endangered wild animals and birds. This program might be sustainable at macro context of the country or at a global level but at the same time because of this many families were forced to migrate from there. This resulted in losing their traditional pasturelands and their crops destroyed by the wild animals. Besides, about ten to twenty individuals were reported to have been killed every year by wild animals.

According to Unni Wikan, we are led to think that sustainability is not always related to natural environment. City dwellers are trying to develop their capacity (the knowledge, skill and social values for their survival) and also trying to build cultural competency. Through cultural competency people have improved their standard of living towards a sustainable life. Sustainability is oriented towards future. The same situation is found among the Kumals of Tumlingtar. When they identified the development, market economy and the new migrants as cultural competent the Kumals formed an organization, educated their children, learned high caste values and practices, adopted new values, established various cooperative groups, formed community forests and identified themselves by their clan names instead of caste. Thus, Kumals have changed a lot to cope up with the present socio-cultural and natural environment. So, a stranger cannot find out a Kumal in Tumlingtaar nowadays by talking only for a short period because the Kumals have not only changed their lifestyle but their occupation, dressing style, language as well as other behaviors and practices.

Finally, I conclude that the concept of sustainability is ambiguous and situational. It has a fluid meaning although it is fruitful to further improve our understanding regarding human adaptation. The aspects of human adaptation are the dimensions of sustainability and each affects the other.

\section{End notes}

The Kumals took initiative from forest user groups in their own leadership when they realized the shortage of forest products.

2 Bourdieu P. (1985) defines various capitals such as social, cultural, political and symbolic capitals

\section{References Cited}

Bourdieu, P., 1985 "The Social Space and the Genesis of Groups." Theory and Society. 14 (6) 723- 44 
Chhetri, R. B., 1999 "Rhetoric and Realities of People's Participation in Conservation and Development in Nepal: An Anthropological Perspective." In R. B. Chhetri and O. P. Gurung (eds.) Anthropology and Sociology of Nepal: Culture, Societies, Ecology and Development.

Daly, H. E., 1991 "Sustainable Growth: An Impossibility Theorem." In Research and Exploration.

Haaland, G., 1990 "Aid and Sustainable Development in a Dual Economy." In Forum for Utviklingsstudier. No 1, Norway, Norsk Utenrikspolitisk Institute.

Haaland, G. et al., 1979 "Interaction between Cultivation and Livestock production in Sami-Arid Africa." In Ecological Studies. No 34

Hardesty, D. L., 1977 Ecological Anthropology. New York, Alfred A. Knof.

Hawley, A. H., 1986 Human Ecology: A Theoretical Essay. London, The University of Chicago Press.

Hardin, G., Nd “The Double C Double P Game.” In Living Within Limits.

Ingold, G., 1992 "Culture and the perception of the Environment." In Elisabeth, C. and David, P. (eds) Bush Base Forest Farm.

Kattel, S. P., 2000 Development and Its Victims: Changing Life-ways of the Kumals from Pottery to Porters. An unpublished M. Phil...thesis submitted to Social Anthropology Department, University of Bergen, Norway.

Moran, E., 1979 Human Adaptability: An Introduction to Ecological Anthropology. Colorado: Westview press.

Milton, K., 1997 "Ecologies: anthropology, culture and the environment." International Social Science Journal. 154(4):478-495

Meadows, D. H. et al., 1992 Beyond the Limits. London: Earthscan publication Ltd.

Pearce, D., 1997 "Sustainable Development: The political and Institutional Challenge.” In (J. Kirkby, et. al., ed.) Sustainable Development. London: Earthscan Publication Limited.

Rappaport, R. A., 979 Ecology, Meaning and Religion. California: North Atlantica Books
Storaas, F., 1997 "The Nexus of Economic and Political Viavility," Research in Economic Anthropology. 18:115-163.

Wikan, U., 1995 "Sustainable Development in the Mega-City," Current Anthropology. 36(4): 635-655. 